\title{
Natural Compounds Isolated from Stachybotrys chartarum Are Potent Inhibitors of Human Protein Kinase CK2
}

\author{
Samer Haidar ${ }^{1,2}{ }^{\mathbb{D}}$, Franziska M. Jürgens ${ }^{1}\left(\mathbb{D}\right.$, Dagmar Aichele ${ }^{1}$, Annika Jagels ${ }^{3,4}$, Hans-Ulrich Humpf ${ }^{4} \mathbb{D}$ \\ and Joachim Jose $1, * \mathbb{D}$
}

1 Institut für Pharmazeutische und Medizinische Chemie, PharmaCampus, Westfälische Wilhelms-Universität Münster, Corrensstr. 48, 48149 Münster, Germany; shaid_01@uni-muenster.de (S.H.); franziska.juergens@uni-muenster.de (F.M.J.); dagmar.aichele@uni-muenster.de (D.A.)

2 Faculty of Pharmacy, Damascus University, 17 April Street, Damascus P.O. Box 9411, Syria

3 Whitney Laboratory for Marine Bioscience, Department of Chemistry, University of Florida, Gainesville, FL 32080, USA; annika.jagels@whitney.ufl.edu

4 Institut für Lebensmittelchemie, Westfälische Wilhelms-Universität Münster, Corrensstr. 45, 48149 Münster, Germany; humpf@uni-muenster.de

* Correspondence: joachim.jose@uni-muenster.de

check for updates

Citation: Haidar, S.; Jürgens, F.M.; Aichele, D.; Jagels, A.; Humpf, H.-U.; Jose, J. Natural Compounds Isolated from Stachybotrys chartarum Are Potent Inhibitors of Human Protein Kinase CK2. Molecules 2021, 26, 4453. https://doi.org/10.3390/molecules 26154453

Academic Editors: Kamelija Zarkovic and Neven Zarkovic

Received: 28 June 2021

Accepted: 20 July 2021

Published: 23 July 2021

Publisher's Note: MDPI stays neutral with regard to jurisdictional claims in published maps and institutional affiliations.

Copyright: (c) 2021 by the authors. Licensee MDPI, Basel, Switzerland. This article is an open access article distributed under the terms and conditions of the Creative Commons Attribution (CC BY) license (https:// creativecommons.org/licenses/by/ $4.0 /)$.

\begin{abstract}
A large number of secondary metabolites have been isolated from the filamentous fungus Stachybotrys chartarum and have been described before. Fourteen of these natural compounds were evaluated in vitro in the present study for their inhibitory activity towards the cancer target CK2. Among these compounds, stachybotrychromene C, stachybotrydial acetate and acetoxystachybotrydial acetate turned out to be potent inhibitors with $\mathrm{IC}_{50}$ values of $0.32 \mu \mathrm{M}, 0.69 \mu \mathrm{M}$ and $1.86 \mu \mathrm{M}$, respectively. The effects of these three compounds on cell proliferation, growth and viability of MCF7 cells, representing human breast adenocarcinoma as well as A427 (human lung carcinoma) and A431 (human epidermoid carcinoma) cells, were tested using EdU assay, IncuCyte ${ }^{\circledR}$ live-cell imaging and MTT assay. The most active compound in inhibiting MCF7 cell proliferation was acetoxystachybotrydial acetate with an $\mathrm{EC}_{50}$ value of $0.39 \mu \mathrm{M}$. In addition, acetoxystachybotrydial acetate turned out to inhibit the growth of all three cell lines completely at a concentration of $1 \mu \mathrm{M}$. In contrast, cell viability was impaired only moderately, to $37 \%, 14 \%$ and $23 \%$ in MCF7, A427 and A431 cells, respectively.
\end{abstract}

Keywords: CK2; natural compounds; antiproliferation; Stachybotrys

\section{Introduction}

Protein kinase CK2, formerly known as Casein Kinase II, is an enzyme localized in both the cytoplasm and the nucleus of cells and appears to be constitutively active [1]. This enzyme is a Ser/Thr kinase, since most if not all of its substrates are phosphorylated at serine or threonine residues [2,3]. CK2 is involved in many cellular processes such as cell cycle regulation, gene expression, tRNA and rRNA synthesis, protein synthesis and degradation, cell growth and differentiation, embryogenesis and apoptosis [4]. CK2 enhances cancer progression by suppressing apoptosis and stimulating cell growth and hence is overexpressed in all types of tumors tested so far. Reducing CK2 activity to levels observed in non-neoplastic cells results in apoptosis, leading to tumor cell death [5]. CK2 is now considered an important drug target for cancer therapy [6]. Natural compounds are one of the major sources to discover new scaffolds for therapeutic purposes. An overwhelming number of natural products with diverse and complex structures which interact with a variety of biological targets are known [7]. Chemical scaffolds evolved by nature can be optimized in their biological activity with the aim of developing new drugs $[7,8]$. The identification of biological active candidates among natural compounds is a challenge since natural products are mainly found in complex mixtures and rather small amounts. Recently, Newman et al. reviewed the use of natural products as a source 
of new drugs over a period of three decades and noticed that around half of the small molecules approved as drugs are natural or naturally derived compounds. Almost two thirds of cancer chemotherapeutics developed from 1981 to 2010 were derived from natural products [8]. This reflects the importance of natural or natural-product-derived compounds as an important source for drug discovery.

Different types of inhibitors of protein kinase CK2 were developed during the last decade [6,9]. Among them, several natural compounds were identified, such as emodin, elagic acid and others [10]. Recently, using an in silico screening approach, the natural compound bikaverin was identified as a potent inhibitor of CK2 [11,12]. Most of the ATP competitive inhibitors of CK2 share common structural features; they consist of planar scaffolds mimicking the adenine or the purine of the ATP with different substituents. Compounds that have been isolated in a previous study from fungal cultures of different Stachybotrys strains share some intriguing structural similarities to known CK2 inhibitors. The natural compounds isolated from the genus Stachybotrys belong to different structural groups, including meroterpenoids containing a chromene ring moiety as well as macrocyclic trichothecenes and phenylspirodrimanes $[13,14]$. Two meroterpenoids exhibited moderate cytotoxic effects on human liver carcinoma cells (HepG2) [14]. In the present follow-up study, fourteen compounds isolated from Stachybotrys chartarum were tested in silico and in vitro on inhibition of CK2. The most active natural compounds were evaluated in terms of impairing cell viability and suppressing cell proliferation in different tumor cell lines.

\section{Results}

\subsection{Inhibition of Human Protein Kinase CK2 by Natural Compounds from} Stachybotrys chartarum

Fourteen compounds which were isolated from Stachybotrys chartarum as described earlier $[13,14]$ were tested for inhibition of human protein CK2 by a CE-based activity assay $[15,16]$. These compounds belong to three different scaffolds (Figure 1), namely: stachybotrychromenes A-C, phenylspirodrimanes (stachybotrydial, stachybotrydial acetate, acetoxystachybotrydial acetate, stachybotrysin B, stachybotrysin C, stachybotrylactam acetate, L-671, stachybonoid D, stachybotryamide) and macrocyclic trichothecenes (satratoxin G, H). All compounds were initially tested for inhibition of CK2 at a concentration of $10 \mu \mathrm{M}$. For compounds showing an inhibition of $50 \%$ or more in comparison to the control with DMSO, an $\mathrm{IC}_{50}$ value was determined (Table 1).<smiles>[R]c1cc(O)c2ccc(CCC=C(C)CCC=C(C)C)ccc1-2</smiles>

(a)

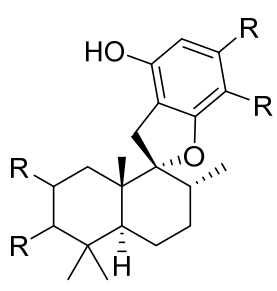

(b)

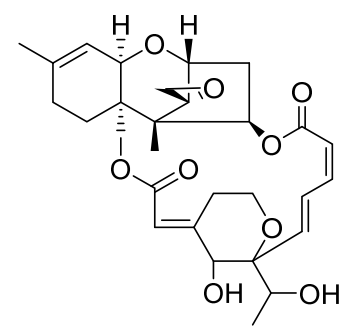

(c)

Figure 1. Chemical backbones of the tested compounds: (a) stachybotrychromenes, (b) phenylspirodrimanes and (c) macrocyclic trichothecenes.

Five compounds, stachybotrychromene $C$, stachybotrydial acetate, acetoxystachybotrydial acetate, stachybotrydial and stachybotrysin B, inhibited human CK2 to more than $50 \%$ at a concentration of $10 \mu \mathrm{M}$ (Table 1 ). For these compounds, the $\mathrm{IC}_{50}$ values were determined using nine different concentrations ranging from $0.001 \mu \mathrm{M}$ to $100 \mu \mathrm{M}$ in appropriate intervals. The most active compound appeared to be stachybotrychromene $\mathrm{C}$ with an $\mathrm{IC}_{50}$ value of $0.32 \mu \mathrm{M}$. Stachybotrychromenes A and B were less active, which might reflect the importance of the two aldehyde groups on the phenol ring, obviously increasing inhibition substantially. All of the phenylspirodrimanes showed inhibition to some extent as well. The 
most active inhibitors from this group turned out to be stachybotrydial acetate followed by acetoxystachybotrydial acetate, with $\mathrm{IC}_{50}$ values of $0.69 \mu \mathrm{M}$ and $1.86 \mu \mathrm{M}$, respectively. Stachybotrydial and stachybotrysin B were obviously less active inhibitors of CK2, with $\mathrm{IC}_{50}$ values of $4.43 \mu \mathrm{M}$ and $13.42 \mu \mathrm{M}$, respectively. This suggests that the two aldehyde groups on the phenol ring together with the one acetoxy group on the drimane skeleton are important for the inhibitory effect. On the other hand, the two macrocyclic trichothecenes, as tested, showed almost no inhibition (Table 1). For comparison, the inhibitory activity of emodin, which is also a natural compound with known CK2 inhibition, was tested in the same assay and an $\mathrm{IC}_{50}$ value of $0.60 \mu \mathrm{M}$ was determined, which was in agreement with the value described earlier [10].

Table 1. Inhibition of human protein kinase CK2 by 14 natural compounds isolated from Stachybotrys chartarum.

\begin{tabular}{|c|c|c|}
\hline Compound Name & Chemical Structure & $\begin{array}{c}\% \text { Inhibition at } 10 \mu \mathrm{M} \\
\left(\mathrm{IC}_{50} \mu \mathrm{M}\right)^{\mathrm{a}}\end{array}$ \\
\hline Stachybotrychromene A & & $\begin{array}{c}26 \\
\text { (n.d.) }\end{array}$ \\
\hline Stachybotrychromene B & & $\begin{array}{c}47 \\
\text { (n.d.) }\end{array}$ \\
\hline Stachybotrychromene C & & $\begin{array}{c}95 \\
(0.32 \pm 0.20)\end{array}$ \\
\hline Stachybotrydial acetate & & $\begin{array}{c}96 \\
(0.69 \pm 0.15)\end{array}$ \\
\hline Acetoxystachybotrydial acetate & & $\begin{array}{c}87 \\
(1.86 \pm 0.36)\end{array}$ \\
\hline Stachybotrydial & & $\begin{array}{c}72 \\
(4.43 \pm 0.30)\end{array}$ \\
\hline Stachybotrysin B & & $\begin{array}{c}50 \\
(13.42 \pm 2.40)\end{array}$ \\
\hline Stachybotrylactam acetate & & $\begin{array}{c}44 \\
\text { (n.d.) }\end{array}$ \\
\hline
\end{tabular}


Table 1. Cont.

\begin{tabular}{|c|c|c|}
\hline Compound Name & Chemical Structure & $\begin{array}{c}\text { \% Inhibition at } 10 \mu \mathrm{M} \\
\left(\mathrm{IC}_{50} \mu \mathrm{M}\right)^{\mathrm{a}}\end{array}$ \\
\hline L-671 & & $\begin{array}{c}42 \\
\text { (n.d.) }\end{array}$ \\
\hline Stachybonoid D & & $\begin{array}{c}47 \\
\text { (n.d.) }\end{array}$ \\
\hline Stachybotrysin C & & $\begin{array}{c}37 \\
\text { (n.d.) }\end{array}$ \\
\hline Stachybotryamide & & $\begin{array}{c}21 \\
\text { (n.d.) }\end{array}$ \\
\hline Satratoxin G & & $\begin{array}{c}12 \\
\text { (n.d.) }\end{array}$ \\
\hline Satratoxin $\mathrm{H}$ & & $\begin{array}{c}10 \\
\text { (n.d.) }\end{array}$ \\
\hline
\end{tabular}

${ }^{a}$ Mean values \pm standard deviation (SD) from three independent experiments. n.d.: not determined.

\subsection{Molecular Docking}

The three most active compounds: stachybotrychromene C, stachybotrydial acetate and acetoxystachybotrydial acetate were docked in the ATP binding site of the CK2 crystal structure (PDB ID: 3C13, resolution $1.95 \AA$ ) [17]. Prior to docking, a conformational search for all compounds was carried out by Molecular Operating Environment (MOE) and the resulting conformations were used for the docking study. The three compounds fit well in the ATP binding site of the enzyme, with an $\mathrm{S}$ score of -7.4925 (stachybotrychromene ${ }^{\circ} \mathrm{C}$ ), -5.1901 (stachybotrydial acetate) and -5.0028 (acetoxystachybotrydial acetate), which are in the same range as the $\mathrm{S}$ score of co-crystallized emodin (-5.852), which has an $\mathrm{IC}_{50}$ value of $0.60 \mu \mathrm{M}$. Figure 2 presents the "Ligand-Protein Contacts Interactions" in 2D and 3D of the three compounds generated with MOE. It appeared that the compounds fit well in the ATP binding site and create adequate bonds. Stachybotrychromene $\mathrm{C}$ is able to create 
a $\pi$-hydrogen bond with the "gatekeeper" residue Ph113 [18], whereas stachybotrydial acetate and acetoxystachybotrydial acetate bind to Val53 by a $\pi$-hydrogen bond (Figure 2).

(a)

(1)

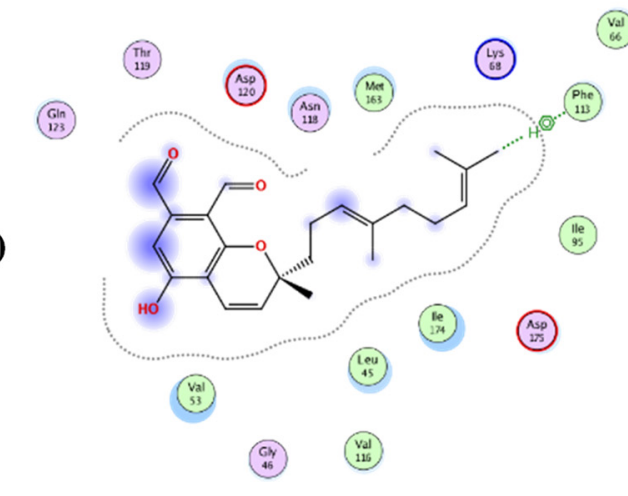

(बis)

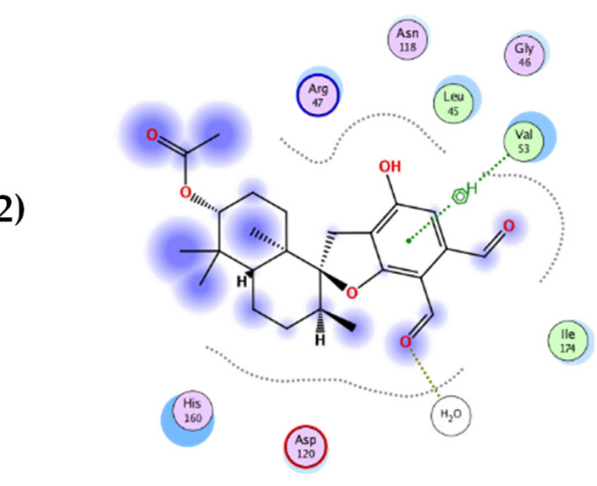

(8:
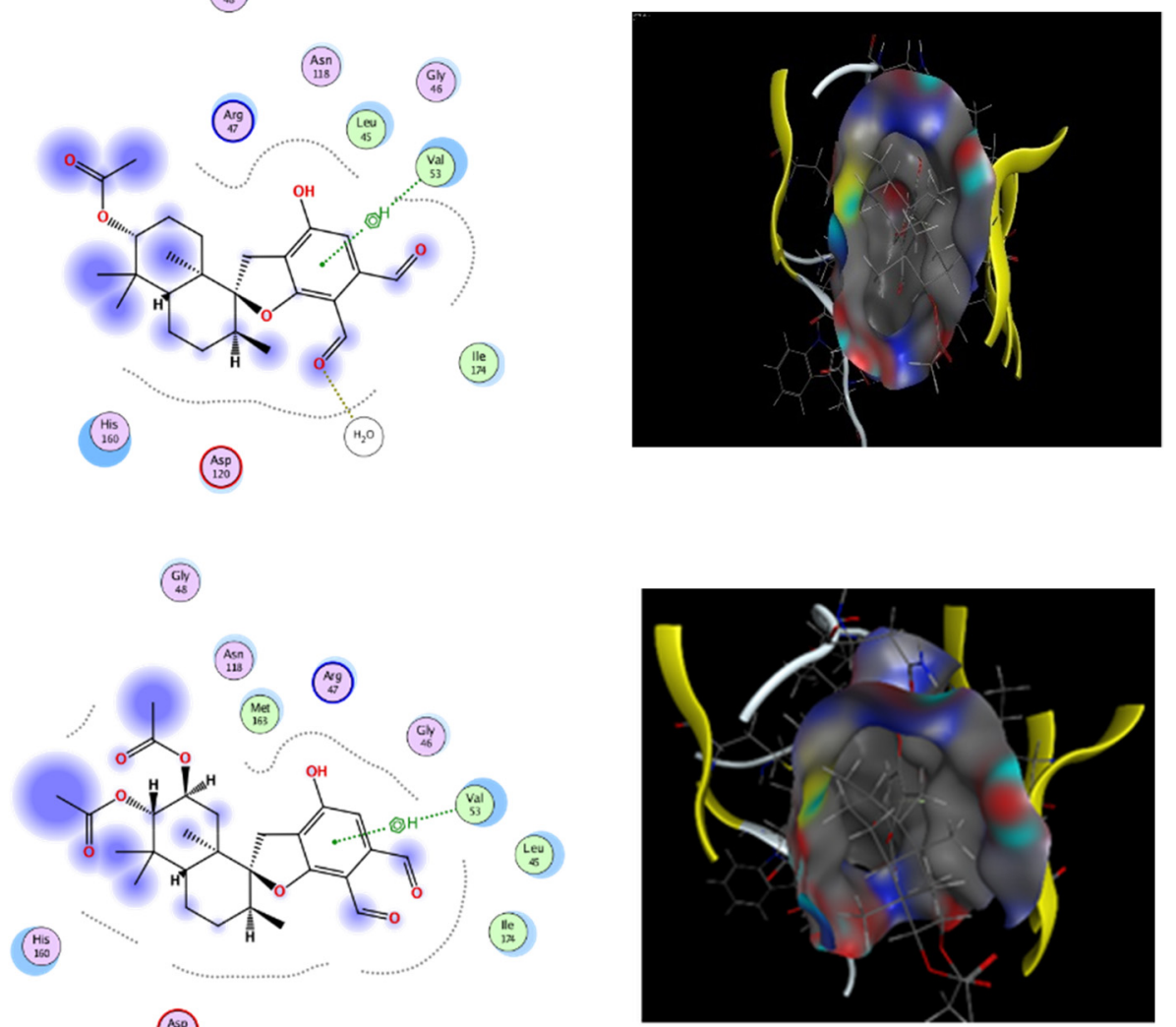

(10D)

(b)

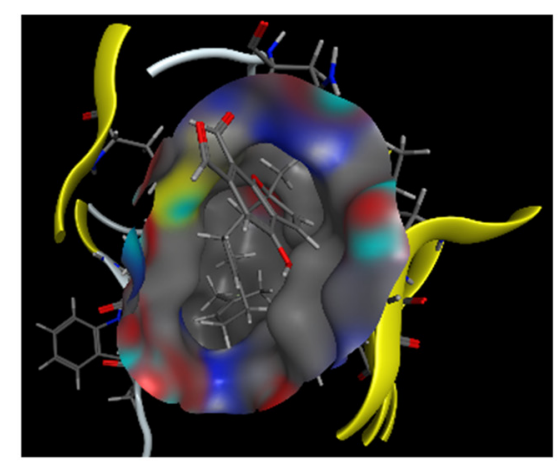




\subsection{ATP Competitive Mode of Action}

Molecular docking revealed that the three most active substances fit well in the ATP binding site. Therefore an ATP-competitive mode of inhibition was investigated. $\mathrm{IC}_{50}$ values of acetoxystachybotrydial acetate were determined in dependency of the co-substrate ATP. Acetoxystachybotrydial acetate was chosen for this purpose because it was available in sufficient quantity. Nine different concentrations of the compound ranging from $0.001 \mu \mathrm{M}$ to $100 \mu \mathrm{M}$ were tested for CK2 inhibition in the presence of three different ATP concentrations $(10 \mu \mathrm{M}, 50 \mu \mathrm{M}, 100 \mu \mathrm{M})$. The IC $_{50}$ values were observed to increase linearly with the ATP concentrations, clearly indicating an ATP competitive mode of inhibition (Figure 3). In the resulting graph, the $K_{i}$ value was determined by the interception of the regression line with the Y-axis, and it turned out to be $1.41 \mu \mathrm{M}$ (Figure 3).

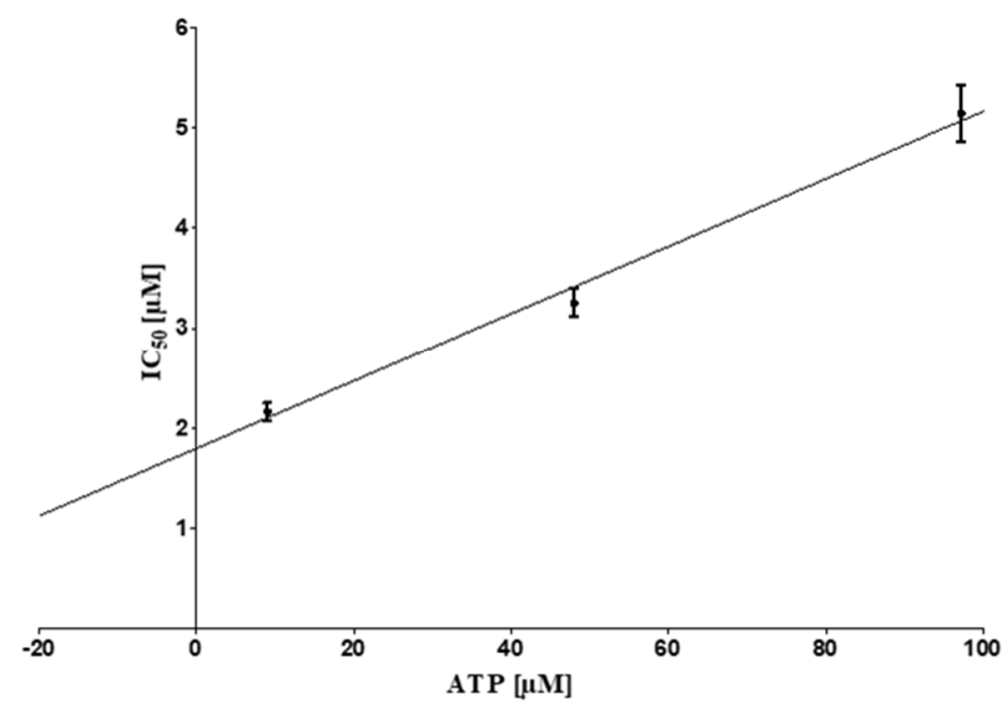

Figure 3. ATP-competitive inhibition of human CK2 by acetoxystachybotrydial acetate. $\mathrm{IC}_{50}$ values with three different ATP concentrations were determined using nine different concentrations of the inhibitor ranging from $0.001 \mu \mathrm{M}$ to $100 \mu \mathrm{M}$ and plotted against the corresponding ATP concentrations. Each $\mathrm{IC}_{50}$ value was determined three times independently. Mean values with standard deviation are given. The Ki value is defined as the Y-axis intercept and was determined to be $1.41 \mu \mathrm{M}\left(\mathrm{R}^{2}=0.97\right)$.

A reaction of aldehyde groups appearing at position $4^{\prime}$ and $5^{\prime}$ of the phenylspirodrimanes such as acetoxystachybotrydial acetate (Figure 1) with amino acids in proteins has been reported before $[19,20]$. The ATP dependency of the $\mathrm{IC}_{50}$ value as shown above is a clear indicator that the interaction between the compound and CK2 seems to be specific and is not due to any non-specific reaction of the dialdehydes of phenylspirodrimanes with amines in a protein. Finally, to rule out this aspect, the inhibitory effect of acetoxystachybotrydial acetate on lactate dehydrogenase (LDH) was determined. Even at a concentration of $10 \mu \mathrm{M}$, no inhibition of LDH by acetoxystachybotrydial acetate was observed, indicating no non-specific interaction of acetoxystachybotrydial acetate by coupling to protein amines (data not shown).

\subsection{Inhibition of Tumor Cell Proliferation}

In order to evaluate a potential anticancer effect of the three most active compounds, MCF7-NucLight Green cells (human breast adenocarcinoma cell line), A427 (human lung carcinoma cell line) and A431 (human epidermoid carcinoma cell line) cells were treated with different concentrations of stachybotrychromene $C$, stachybotrydial acetate and acetoxystachybotrydial acetate. First, the inhibition of tumor cell growth was evaluated by determining the confluence after treatment with the selected compounds using an IncuCyte $^{\circledR}$ live cell imager. Cell growth of MCF7 NucLight Green and A431 cells was 
completely blocked by the addition of $1 \mu \mathrm{M}$ of acetoxystachybotrydial acetate (Figure 4), whereas the growth of A427 was strongly impaired at this concentration. Stachybotrydial acetate showed no effect on cell growth of MCF7 NucLight green or A427 and A431 cells in a concentration of $1 \mu \mathrm{M}$, but growth of all cell lines was completely blocked at a concentration of $100 \mu \mathrm{M}$ in the case of this compound. Stachybotrychromene $\mathrm{C}$ showed no inhibition of growth in any cell line at a concentration of $1 \mu \mathrm{M}$. However, it was able to reduce the growth of MCF7 NucLight Green cells, at a concentration of $100 \mu \mathrm{M}$ (data not shown), whereas no other cell line was affected.

MCF7

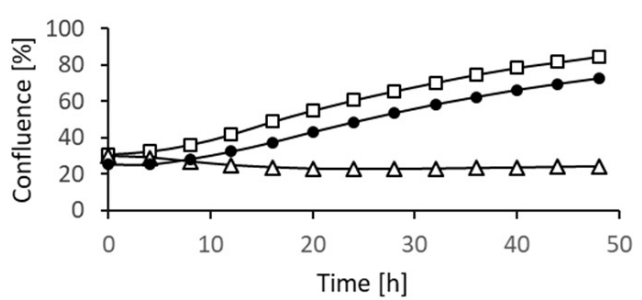

A427

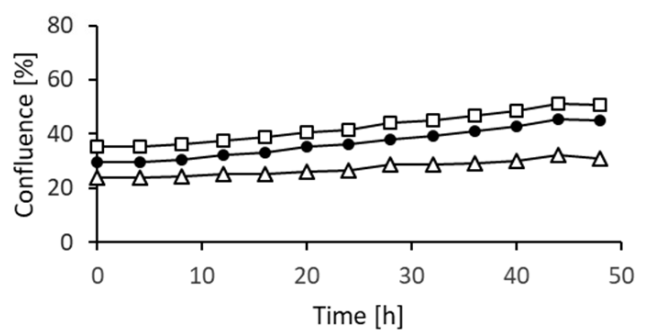

A431

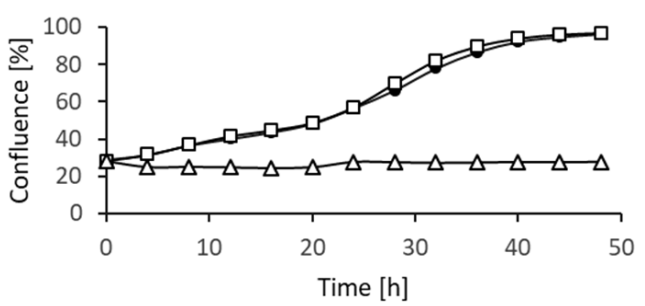

(a)

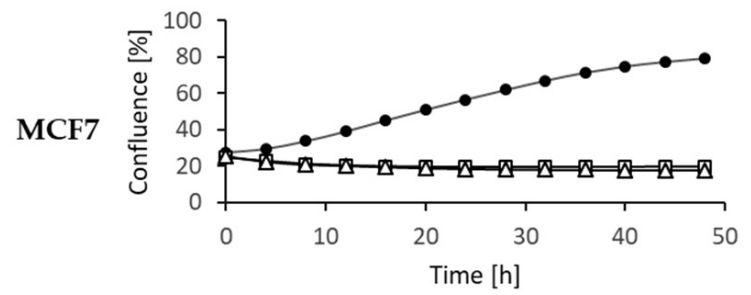

A427

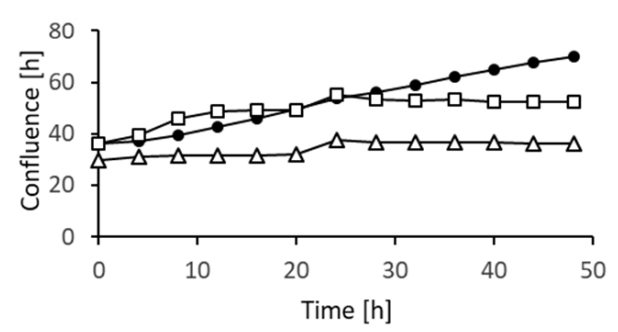

A431

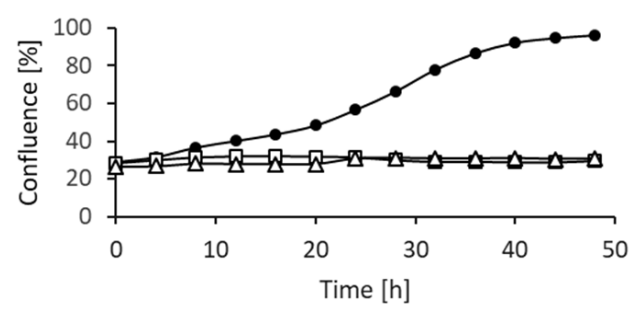

(b)

Figure 4. Inhibition of tumor cell growth by (a) stachybotrydial acetate and (b) acetoxystachybotrydial acetate. MCF7 NucLight Green cells, A431 cells and A427 cells were treated with $1 \mu \mathrm{M}(\square)$ and $100 \mu \mathrm{M}(\Delta)$ of stachybotrydial acetate or acetoxystachybotrydial acetate or $1 \%$ DMSO as control $(\bullet)$ for $48 \mathrm{~h}$. Cell confluence was monitored over $48 \mathrm{~h}$ using IncuCyte $^{\circledR}$ S3 live cell imaging system and analyzed using the IncuCyte ${ }^{\circledR}$ S3 2017A software.

In Figure 5, the morphology of MCF7 NucLight Green after treatment with $1 \mu \mathrm{M}$ of acetoxystachybotrydial acetate for $24 \mathrm{~h}$ and $48 \mathrm{~h}$ is shown. Cells treated with $1 \%$ DMSO were used as a control and the morphology was recorded by the IncuCyte ${ }^{\circledR}$ live cell imager. Compared with the control, the total number of MCF7 NucLight Green cells was strongly reduced after incubation with $1 \mu \mathrm{M}$ of acetoxystachybotrydial acetate for $48 \mathrm{~h}$. A similar image could be observed after $24 \mathrm{~h}$ as well. Furthermore, shrinkage of cells was monitored and their morphology changed to a more spherical shape after treatment with the compound. A427 and A431 cells exhibited similar changes in morphology after treatment with $1 \mu \mathrm{M}$ of acetoxystachybotrydial acetate for $48 \mathrm{~h}$ (Figure 5). 


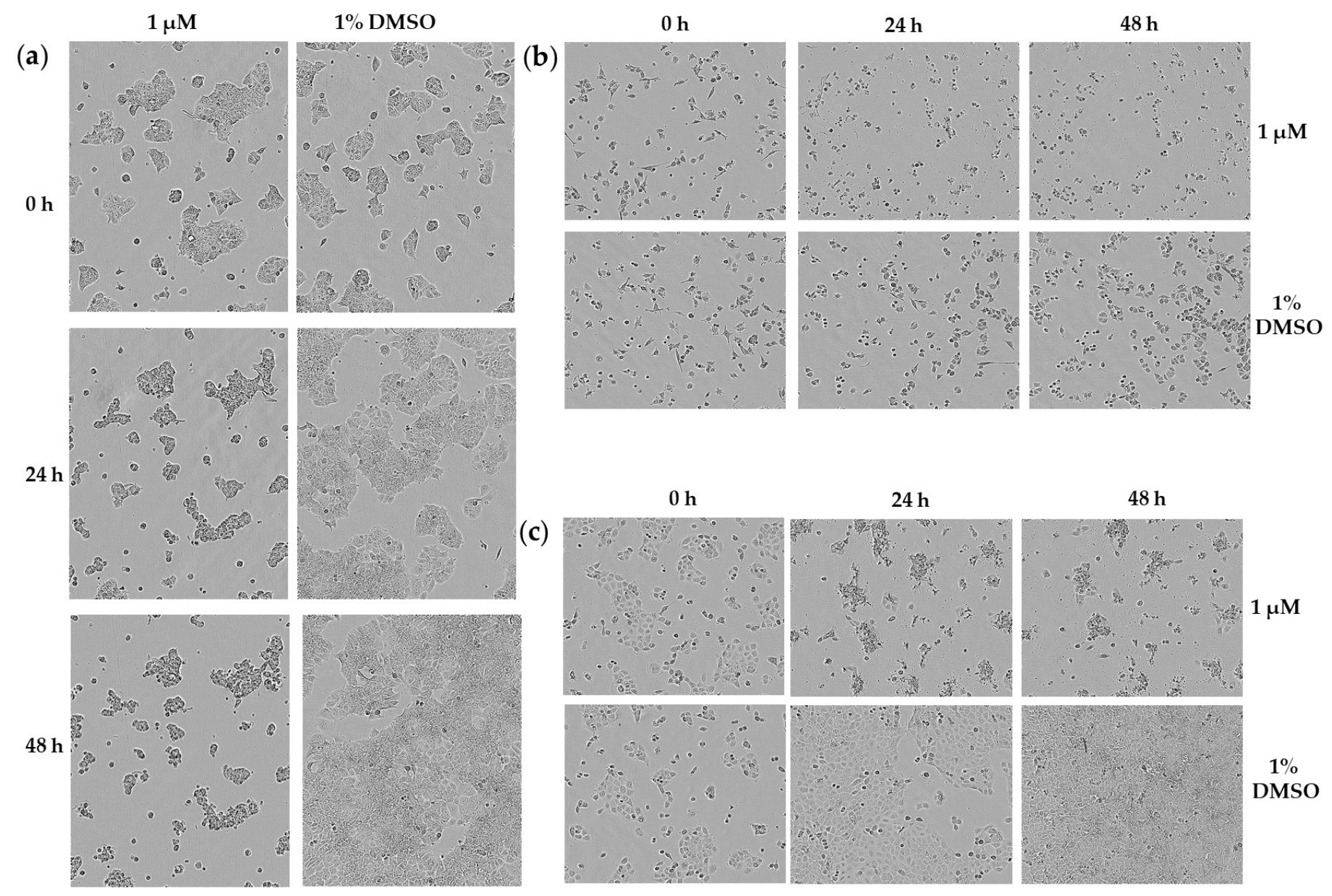

Figure 5. Phase contrast images of (a) MCF7 cells, (b) A427 cells and (c) A431 cells treated with acetoxystachybotrydial acetate in a concentration of $1 \mu \mathrm{M}$ and $1 \%$ DMSO as control at $0 \mathrm{~h}, 24 \mathrm{~h}$ and $48 \mathrm{~h}$ after treatment. Images were taken at tenfold magnification on IncuCyte ${ }^{\circledR}$ live cell imager.

Inhibition of cell proliferation was determined by the EdU assay in MCF7 NucLight Green cells after $24 \mathrm{~h}$ incubation with $1 \mu \mathrm{M}$ or $100 \mu \mathrm{M}$ acetoxystachybotrydial acetate. Proliferating cells are recognized by red fluorescence due to coupling of 5-TAMRA-PEG3azide to the modified nucleotide incorporated in case of DNA replication (Figure 6).

Less than $1 \%$ of MCF7 cells were still proliferating after treatment with $1 \mu \mathrm{M}$ of acetoxystachybotrydial acetate (Figure 7). To obtain a similar effect on MCF7 cells with stachybotrydial acetate, a concentration of $100 \mu \mathrm{M}$ was necessary, but still, the number of proliferating cells was obviously higher than with $1 \mu \mathrm{M}$ acetoxystachybotrydial acetate. In contrast, stachybotrychromene C showed only negligible effects on MCF7 cell proliferation, even at concentrations of $100 \mu \mathrm{M}$. To evaluate the results obtained with acetoxystachybotrydial acetate, emodin, a known natural inhibitor of CK2 as described above, was applied in the same assay. At a concentration of $100 \mu \mathrm{M}$ emodin, $5 \%$ of the MCF7 cells were proliferating, at a concentration of $10 \mu \mathrm{M}, 77 \%$ were proliferating and at a concentration of $1 \mu \mathrm{M}$, no effect on MCF7 tumor cell proliferation was detectable (data not shown). This indicates that acetoxystachybotrydial acetate is a more potent inhibitor of tumor cell proliferation, at least in the case of MCF7 breast cancer cells, than the known inhibitor of human protein kinase CK2, emodin. 
(a)
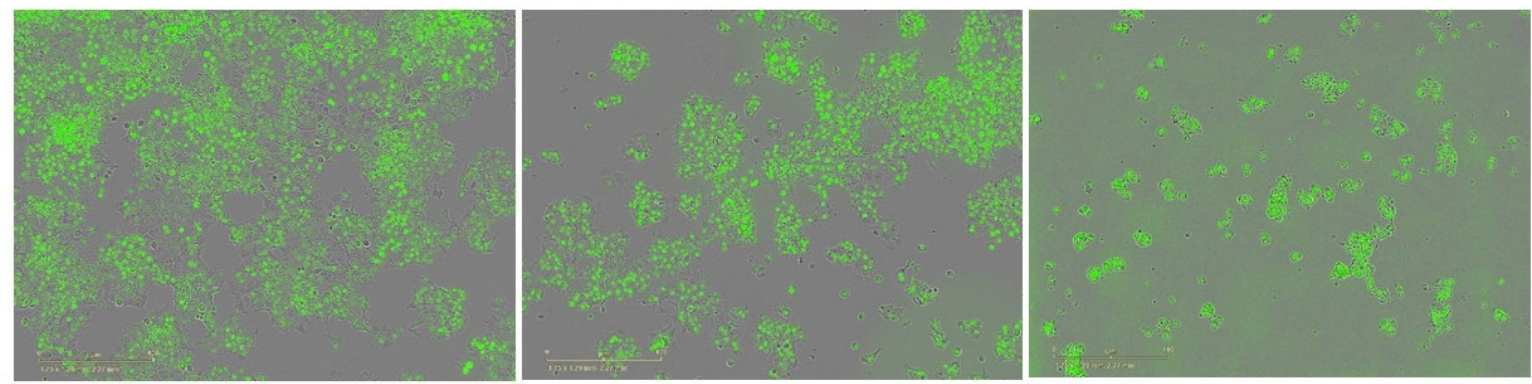

(b)

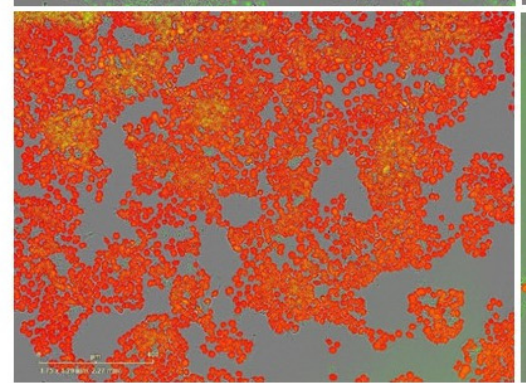

DMSO

$1 \%$

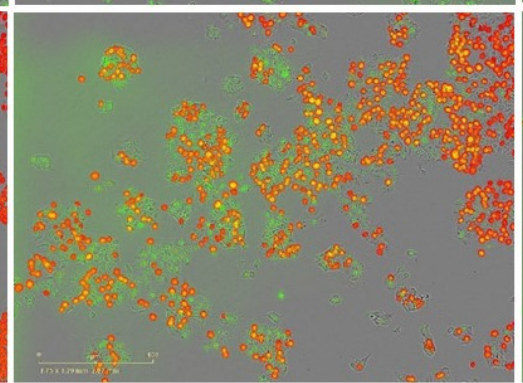

stachybotrydial acetate $100 \mu \mathrm{M}$

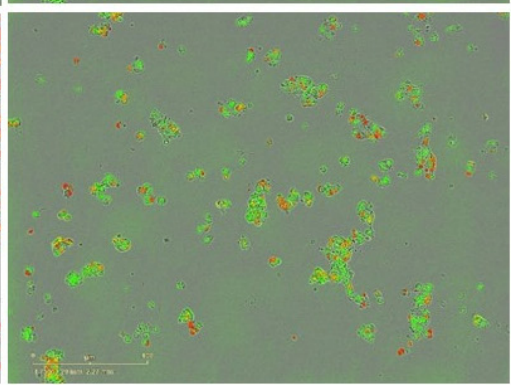

acetoxystachybotrydial acetate $1 \mu \mathrm{M}$

Figure 6. Fluorescence images of MCF7 NucLight green cells treated with 1\% DMSO, $100 \mu \mathrm{M}$ stachybotrydial acetate or $1 \mu \mathrm{M}$ acetoxystachybotrydial acetate for $24 \mathrm{~h}$. (a) Detection of cells by their green fluorescent nuclei. (b) Proliferating cells were detected by an additional staining of cell nuclei by the EdU assay using 5-TAMRA-PEG3-azide as a coupled fluorophore. Thus, proliferating cells were monitored by red fluorescence. The pictures in lane (b) are an overlay of the green fluorescence images of MCF7 NucLight green and the red fluorescence images showing TAMRA-labeled proliferating cells. Cells that are emitting only green fluorescence are not proliferating, in contrast to those emitting an additional red fluorescence. Images were taken at tenfold magnification on IncuCyte ${ }^{\circledR}$ live cell imager.

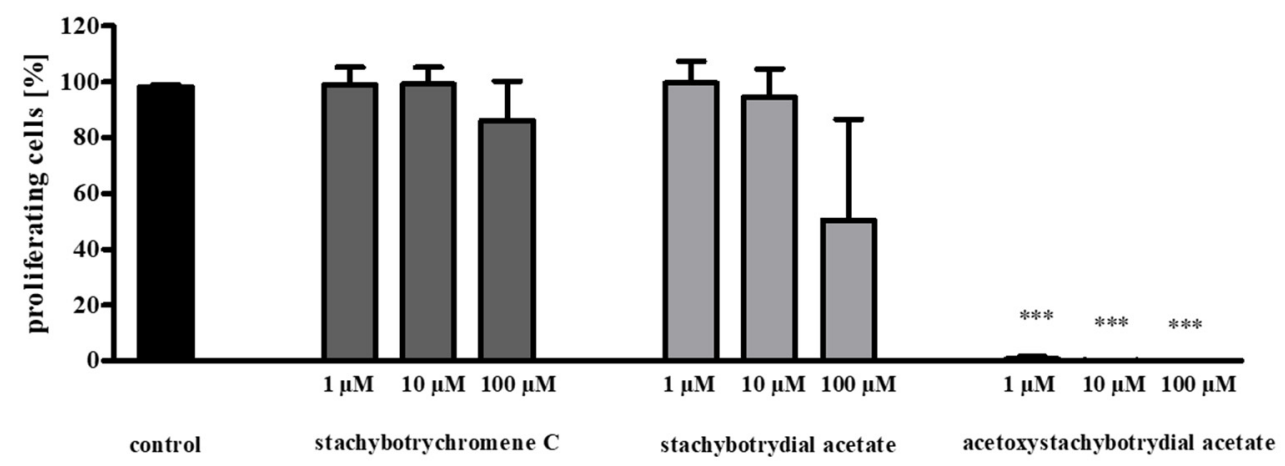

Figure 7. Quantification of the antiproliferative effect of stachybotrychromene C, stachybotrydial acetate and acetoxystachybotrydial acetate on MCF7 NucLight Green cells after $24 \mathrm{~h}$ of incubation. Numbers of proliferating cells were determined by EdU assay. Results are shown as a percent of proliferating cells relative to control cells (with 1\% DMSO) and represent the mean $( \pm \mathrm{SD})$ of three independent experiments. ${ }^{* * *} p<0.001$.

The $\mathrm{EC}_{50}$ value of acetoxystachybotrydial acetate for the inhibition of tumor cell proliferation after $24 \mathrm{~h}$ was determined for MCF7 NucLight green cells (Figure 8) and appeared to be $0.39 \mu \mathrm{M}$. 


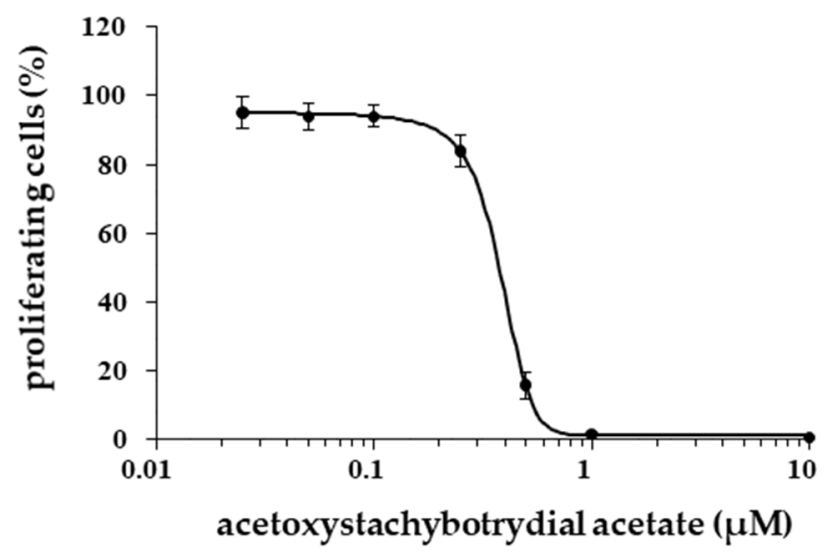

Figure 8. Dose-dependent inhibition of MCF7 NucLight green cell proliferation by acetoxystachybotrydial acetate using EdU assay. The $\mathrm{EC}_{50}$ is $0.39 \pm 0.02 \mu \mathrm{M}$, which was determined in three independent replications. Mean values with standard deviations are given.

Furthermore, cell viability was tested with the MTT assay for the three cell lines mentioned above. Stachybotrychromene C, stachybotrydial acetate and acetoxystachybotrydial acetate were applied in concentrations of $1 \mu \mathrm{M}$ and $100 \mu \mathrm{M}$ for $48 \mathrm{~h}$ (Figure 9). Treatment of A427 and A431 cells with $1 \mu \mathrm{M}$ of stachybotrychromene $\mathrm{C}$ for $48 \mathrm{~h}$ caused a moderate reduction of cell viability by $32 \%$ and $27 \%$, respectively. Almost no further reduction was seen with a concentration of $10 \mu \mathrm{M}$ (data not shown) and only a slight increase of inhibitory effect by nearly $10 \%$ was obtained with a concentration of $100 \mu \mathrm{M}$ (Figure 9 ). Viability of MCF7 cells was not decreased by adding a concentration of $100 \mu \mathrm{M}$, but was increased to $155 \%$ of the control by adding $1 \mu \mathrm{M}$ of stachybotrychromene $\mathrm{C}$. The same was observed for MCF7 cells when incubated with $1 \mu \mathrm{M}$ of stachybotrydial acetate. At a concentration of $100 \mu \mathrm{M}$, stachybotrydial acetate reduced cell viability by $86 \%, 82 \%$ and $93 \%$ of the control in MCF7, A427 and A431, respectively, resulting in only residual cellular activity. At a concentration of $10 \mu \mathrm{M}$, reduction of cell viability in A427 and A431 was not significant, whereas cell viability of MCF7 was slightly increased (by $20 \%$, data not shown). Treatment with $1 \mu \mathrm{M}$ of the compound results in a reduction of cell viability in A427 and A431 cells to $86 \%$ and $73 \%$ of the control. The most striking effect on cell viability was observed for acetoxystachybotrydial acetate with residual 2\% (MCF7), 12\% (A427) and 5\% (A431) of cell viability after $48 \mathrm{~h}$ at $100 \mu \mathrm{M}$. At a concentration of $1 \mu \mathrm{M}$, a reduction of cell viability to $37 \%$ for MCF7, $12 \%$ for A427 and 23\% for A431 cells was observed.

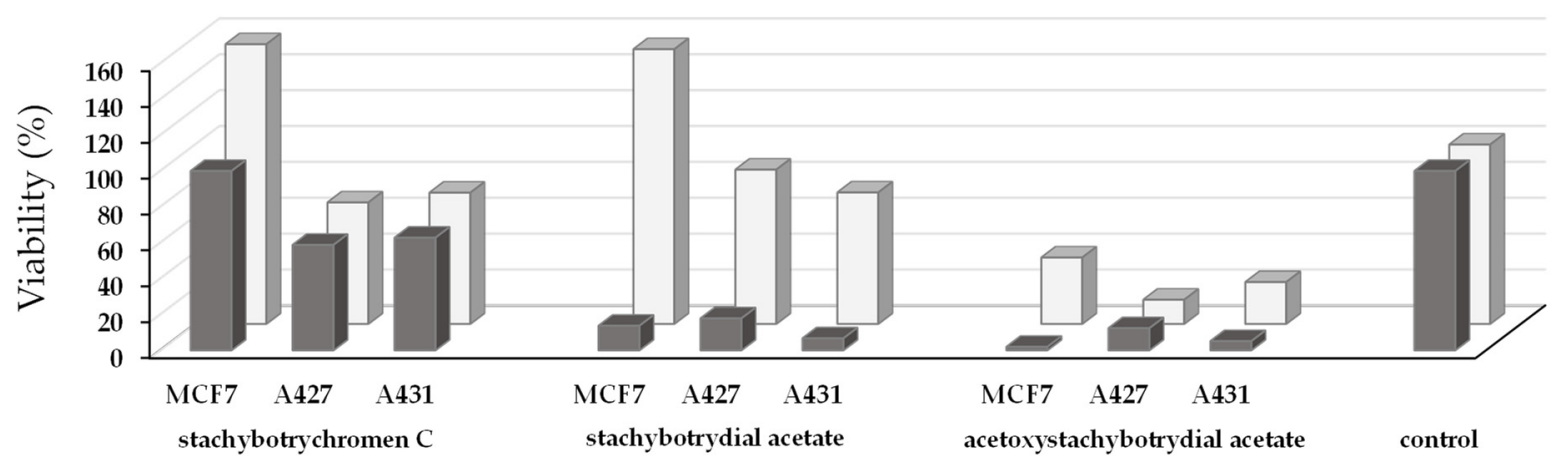

Figure 9. Cell viability of MCF7, A427 and A431 cells after $48 \mathrm{~h}$ treatment with stachybotrychromene C, stachybotrydial acetate and acetoxystachybotrydial acetate as tested by MTT assay at a concentration of $100 \mu \mathrm{M}$ (dark gray) and at a concentration of $1 \mu \mathrm{M}$ (light gray) in three independent experiments. 


\section{Discussion}

Protein kinase CK2, which is involved in cell proliferation and survival, is overexpressed in different human cancers. Selecting new hits with significant inhibitory activity toward this enzyme will definitely contribute to finding new drugs for the treatment of cancers from different origins. In this work, we demonstrated that three isolated natural products from Stachybotrys chartarum $[13,14]$, namely, stachybotrychromene C, stachybotrydial acetate and acetoxystachybotrydial acetate were potent $\mathrm{CK} 2$ inhibitors with $\mathrm{IC}_{50}$ values in the low $\mu \mathrm{M}$ range. Stachybotrydial acetate and stachybotrychromene $C$ showed only minor effects on tumor cell growth and tumor cell proliferation even at $100 \mu \mathrm{M}$ concentration, whereas acetoxystachybotrydial acetate almost completely blocked tumor cell growth and tumor cell proliferation at a concentration of $1 \mu \mathrm{M}$. For the inhibition of tumor cell proliferation in MCF7 breast cancer cells, an $\mathrm{EC}_{50}$ value of $0.39 \mu \mathrm{M}$ was obtained. In contrast to this, effects on cell viability were not as strong as effects on cell growth and proliferation. This implies that the anticancer effects are not simply due to cytotoxic effects. It is noteworthy that the $\mathrm{EC}_{50}$ value of acetoxystachybotrydial acetate for MCF7 cells $(0.39 \mu \mathrm{M})$ was in the submicromolar range, and even much lower compared to the $\mathrm{EC}_{50}$ values of other human CK2 inhibitors such as bikaverin $(1.97 \mu \mathrm{M})$ [12] or DMAT-derived hydroxamates $(9.02 ; 9.97$ and $15.66 \mu \mathrm{M})$ [21]. As described, acetoxystachybotrydial acetate was very effective in different cancer cell lines, whereas the most active compound towards the target enzyme CK2, which was stachybotrychromene C, showed much less effect in the cellular assays. The possibility cannot be excluded that this is partially due to the $\log P$ values of the compounds, which were calculated to be 6.04 for stachybotrychromene C, 2.81 for acetoxystachybotrydial acetate and 3.43 for stachybotrydial acetate. Overly high $\log P$ values, as seen here for stachybotrychromene $C$, could have a negative effect on membrane permeability of a compound and hence on its cellular uptake.

Cytotoxicity of stachybotrychromenes A-C was determined earlier on HepG2 cells, using a resazurin reduction assay and no or moderate effects were detectable [14]. These results are in accordance with the results obtained in this study for stachybotrychromene $C$ with three different cancer cell lines, MCF7, A427 and A431. It is important to note that several meroterpenoid compounds were reported to have broad biological activities, such as immune toxicity, neurotoxicity, cytotoxicity, fibrinolysis, antiviral and anti-plasmodial activity [22-24]. However, to the best of our knowledge, none of these compounds were evaluated towards inhibition of any protein kinase before. In this work, several compounds isolated from the filamentous fungus Stachybotrys chartarum were shown to be potent CK2 inhibitors; among them, acetoxystachybotrydial acetate showed considerable effects on cell viability and cell proliferation. The compounds described in this work as CK2 inhibitors belong to two different backbones and can serve as a starting point for the discovery of more active derivatives.

\section{Materials and Methods}

\subsection{The Compounds}

Emodin was purchased from Merck Millipore (Darmstadt, Germany). All commercial reagents were of the highest available purity grade. The compounds were dissolved in dimethyl sulfoxide (DMSO) and the stock solutions were stored at $-20^{\circ} \mathrm{C}$ and warmed to $25^{\circ} \mathrm{C}$ just before use. The isolation of compounds obtained from Stachybotrys chartarum has been described earlier $[13,14]$.

\subsection{Inhibition of Human CK2 Holoenzyme}

The selected natural compounds were tested for their inhibitory activity towards the human recombinant CK2 holoenzyme in a Capillary Electrophoresis (CE)-based assay following the procedure described earlier [15]. The synthetic peptide RRRDDDSDDD was used as a substrate, which was reported to be efficiently phosphorylated by CK2. The purity of the CK2 holoenzyme as applied was beyond 99\%. For initial testing, inhibition was determined relative to the controls at inhibitor concentrations of $10 \mu \mathrm{M}$ in DMSO as a 
solvent. The reaction with pure solvent without inhibitor was used as a control and set to $0 \%$ inhibition. Reactions without CK2 were used as negative control and were taken as $100 \%$ inhibition. $\mathrm{IC}_{50}$ values were determined by measuring $\mathrm{CK} 2$ inhibition at nine different concentrations of inhibitors ranging from $0.001 \mu \mathrm{M}$ to $100 \mu \mathrm{M}$ in appropriate intervals and calculated from the resulting dose-response curve [16]; Prism 6 (GraphPad Software, San Diego, CA, USA) was used to estimate the $\mathrm{IC}_{50}$ values. For the determination of the mode of inhibition, the ATP concentration in the assay buffer was varied to 10,50 and $100 \mu \mathrm{M}$, while the rest of the procedure was identical to the $\mathrm{IC}_{50}$ determination described above.

\subsection{Cultivation of Cancer Cell Lines}

MCF7 NucLight Green cells (human breast adenocarcinoma cell line), provided from Essen Bioscience, Royston, UK, were cultured in Eagle's Minimum Essential Medium (EMEM) supplemented with $2 \mathrm{mM}$ L-glutamine, $0.01 \mathrm{mg} / \mathrm{mL}$ human recombinant insulin, 10\% Fetal Calf Serum (FCS), 1\% Penicillin/Streptomycin (Pen/Strep) and $0.5 \mu \mathrm{g} / \mathrm{mL}$ puromycin (every second passage) [25]. Human epidermoid carcinoma cells A431 (kindly provided by the Department of Experimental Tumor Biology, WWU Münster, Germany) were cultured in Dulbecco's Modified Eagle's Medium (DMEM) high glucose, supplemented with $2 \mathrm{mM} \mathrm{L-glutamine}$ and 10\% FCS. For cultivation of A427 human lung carcinoma cell line (purchased from German Collection of Microorganisms and Cell Cultures (DSMZ), No. ACC234, Braunschweig, Germany), Roswell Park Memorial Institute, medium (RPMI1640) supplemented with $2 \mathrm{mM}$ L-glutamine and 10\% FCS was used. For testing CK2 inhibitors on cell growth, cell proliferation or cell viability, cells were seeded at a density of $5 \times 10^{3}$ cells per well (A431, A427) or $1 \times 10^{4}$ cells per well (MCF7 NucLight Green) into 96-well culture plates. After overnight incubation at $37^{\circ} \mathrm{C}$ in a humidified atmosphere $\left(5 \% \mathrm{CO}_{2}\right)$, seeding medium was removed and replaced with fresh medium containing the compounds at 1, 10 or $100 \mu \mathrm{M}$. DMSO at a final concentration of $1 \%$ served as a control. Cells were subsequently incubated for a further 24 or $48 \mathrm{~h}$ at $37^{\circ} \mathrm{C}$ in a humidified atmosphere $\left(5 \% \mathrm{CO}_{2}\right)$.

\subsection{Cell Proliferation}

Cell proliferation of MCF7 NucLight green cells was quantified by the EdU-click assay (Baseclick BCK-EdU555-1, Baseclick GmbH, Munich, Germany). The nucleoside analog 5-ethynyl-2'-deoxyuridine (EdU) is incorporated during DNA synthesis, and a 5carboxytetramethylrhodamin-triethylene glycol-azide (5-TAMRA-PEG3-azide) fluorophore used for detection is coupled by click reaction. MCF7 NucLight green cells were incubated with the inhibitors for $24 \mathrm{~h}$. Medium was replaced with medium containing $10 \mu \mathrm{M}$ EdU. After a further $24 \mathrm{~h}$, the 5-TAMRA-PEG3-azide fluorophore was added as described in the Baseclick assay manual. The results were given as a percent ratio of proliferating cells relative to cells treated with $1 \%$ DMSO as a control. The effects of CK2 inhibitors were analyzed in triplicate and all experiments were repeated three times independently.

\subsection{Cell Viability Assay}

The effect of CK2 inhibitors on the viability of MCF7 NucLight green, A427 and A431 cells was evaluated using MTT assay [26]. This is a colorimetric assay, which measures the conversion of 3-(4,5-dimethylthiazol-2-yl)-2,5-diphenyltetrazolium bromide (MTT) into violet formazan that is produced by succinate dehydrogenase of the intact mitochondria in viable cells. MTT assay was performed in 96-well plates. Cells were seeded at a density of $5 \times 10^{3}$ cells per well (A431, A427), or $1 \times 10^{4}$ cells per well (MCF7 NucLight Green). After overnight incubation, seeding medium was removed and replaced with fresh medium containing the inhibitor at 1,10 or $100 \mu \mathrm{M}$. DMSO at a final concentration of $1 \%$ served as a control. Cells were incubated for $48 \mathrm{~h}$ at $37^{\circ} \mathrm{C}$ in a humidified atmosphere $\left(5 \% \mathrm{CO}_{2}\right)$. Afterwards, MTT reagent (Sigma Aldrich, Steinheim am Albuch, Germany) was added at a final concentration of $0.5 \mathrm{mg} / \mathrm{mL}$. After incubation for $2 \mathrm{~h}$ at $37^{\circ} \mathrm{C}$, the medium was 
discarded and $200 \mu \mathrm{L}$ DMSO was added to solve the resulting formazan. After mixing, the absorption was determined at $570 \mathrm{~nm}$ with a reference wavelength of $630 \mathrm{~nm}$ using a microplate reader. CK2 inhibitors were assayed in triplicate, and the experiments were repeated three times.

\subsection{IncuCyte ${ }^{\circledR}$ Cytotoxicity Assay}

The IncuCyte ${ }^{\circledR}$ S3 Live-Cell Analysis System (Ann Arbor, MI, USA) was used for monitoring cell growth and to determine the cytotoxic effect of tested compounds in the three cell lines. This technique allows an automated in-incubator method of live cell monitoring. The concentration-dependent growth-enhancing/growth-inhibitory activity of the tested compound was evaluated against the above mentioned cell lines. After addition of inhibitors in concentrations of $1 \mu \mathrm{M}, 10 \mu \mathrm{M}$ and $100 \mu \mathrm{M}$, cell growth was monitored for $48 \mathrm{~h}$ by generating phase contrast images. Growth curves were generated by the algorithm in the "2017A Rev2" software from data points acquired during $2 \mathrm{~h}$ interval imaging. All samples were plated in triplicate.

\subsection{LDH Assay}

For the determination of enzymatic activity of lactate dehydrogenase (LDH), $0.25 \mu \mathrm{g}$ of LDH-5 from rabbit muscle (Roche Diagnostics GmbH, Mannheim, Germany) was incubated in phosphate buffered saline (PBS) containing $0.25 \mathrm{mM}$ nicotinamide adenine dinucleotide (NADH) and $0.625 \mathrm{mM}$ pyruvate in a total volume of $1 \mathrm{~mL}$ at room temperature. Absorption at $340 \mathrm{~nm}$ was monitored every $5 \mathrm{~s}$ within $5 \mathrm{~min}$. For the determination of inhibitory activity of phenylspirodrimanes towards $\mathrm{LDH}$, acetoxystachybotrydial acetate was added in a final concentration of $10 \mu \mathrm{M} ; 0.1 \%$ DMSO served as a control.

\subsection{Computational Study}

Molecular Operating Environment software package (MOE, Chemical Computing Group, Montreal, QC, Canada) [27] running on Intel Core, i5-6500CPU, $3.20 \mathrm{GHz}$ processor was used to perform this study.

\subsubsection{Database Generation}

The selected compounds were rebuilt with MOE building option implemented in the software. The compounds were optimized by adding hydrogen atoms using the option of MOE software. The energy of the compounds was minimized using the following parameters: gradient: 0.05, Force Field: MMFF94X, Chiral constraint and Current Geometry. The conformation methodology was used to develop low energy conformations for each compound, applying the LowModMD method with RMS gradient of 0.05; all other parameters were used as default. All of the compounds and their conformations were saved in mdb database and employed for docking studies later.

\subsubsection{Protein Structure Preparation and Molecular Docking}

Three-dimensional structure of the CK2 complex with emodin was obtained from the Protein Data Bank (PDB) using PDB ID: (3C13) having a resolution of $1.95 \AA$ A17]. The structure was optimized by using QuickPrep function implemented in the MOE software package [27]. In the second step, energy minimization was performed using default parameters, where the force field was Amber 10. The docking of the selected compounds into the active site of the CK2 enzyme (3C13) was achieved using MOE-Dock implemented in MOE. The docking parameters were set as Rescoring 1: London dG, Placement: triangle matcher, Retain 30, Refinement Force field and Rescoring 2: GBVI/WSA dG, Retain 30. The docking simulations of MOE predicted the most favorable conformations of each compound to obtain the minimum energy structure. The top conformation for each compound was selected based on the $S$ score and visual inspection in 2D and 3D. Prior to docking, the initial ligand from the complex structure was extracted. For the scoring function, lower scores indicated more favorable poses. The unit for the scoring function was $\mathrm{Kcal} / \mathrm{mol}$, 
and the $\mathrm{S}$ score referred to the final score, which was the score of the last stage that was not set to None. The Lig X function in MOE was used for conducting interactive ligand modification and energy minimization in the active site of the receptor.

\subsection{Statistical Analysis}

All statistical analyses and statistical diagrams were generated with Prism 6 software (GraphPad Software, San Diego, CA, USA).

Author Contributions: S.H. participated in the in vitro assay, performed the docking and wrote the manuscript; F.M.J. performed the in vitro assay, most of the cell assays and wrote parts of the manuscript; D.A. managed the cellular assays and wrote parts of the manuscript; A.J. prepared the compounds; H.-U.H. prepared the compounds and critically read the manuscript; J.J. designed and coordinated the project, analyzed the results and wrote parts of the manuscript. All authors have read and agreed to the published version of the manuscript.

Funding: This research received no external funding.

Institutional Review Board Statement: Not applicable.

Informed Consent Statement: Not applicable.

Data Availability Statement: Data reported in this study is contained within the article. The underlying rawdata is available on request from the corresponding author.

Acknowledgments: The authors would like to thank Indra Finger for her participation in cell culture experiments.

Conflicts of Interest: The authors report no conflicts of interest. The authors alone are responsible for the content and writing of this article.

Sample Availability: The compounds were isolated in small amounts from fungal cultures according to ref. [13] and are no longer available.

\section{References}

1. Pinna, L.A. Protein kinase CK2: A challenge to canons. J. Cell Sci. 2002, 115, 3873-3878. [CrossRef] [PubMed]

2. Salvi, M.; Sarno, S.; Cesaro, L.; Nakamura, H.; Pinna, L.A. Extraordinary pleiotropy of protein kinase CK2 revealed by weblogo phosphoproteome analysis. BBA-Mol. Cell Res. 2009, 1793, 847-859. [CrossRef] [PubMed]

3. Vilk, G.; Weber, J.E.; Turowec, J.P.; Duncan, J.S.; Wu, C.; Derksen, R.; Zien, P.; Sarno, S.; Donella-Deana, A.; Lajoie, G.; et al. Protein kinase CK2 catalyzes tyrosine phosphorylation in mammalian cells. Cell. Signal. 2008, 20, 1942-1951. [CrossRef] [PubMed]

4. Ghavidel, A.; Schultz, M.C. TATA binding protein-associated CK2 transduces DNA damage, signals to the RNA polymerase III transcriptional machinery. Cell 2001, 106, 575-584. [CrossRef]

5. Ahmad, K.A.; Wang, G.; Unger, G.; Slaton, J.; Ahmed, K. Protein kinase CK2-A key suppressor of apoptosis. Adv. Enzym. Regul. 2008, 48, 179-187. [CrossRef] [PubMed]

6. Cozza, G.; Pinna, L.A. Casein kinases as potential therapeutic targets. Expert Opin. Ther. Targets 2016, 20, 319-340. [CrossRef]

7. Patridge, E.; Gareiss, P.; Kinch, M.S.; Hoyer, D. An analysis of FDA-approved drugs: Natural products and their derivatives. Drug Discov. Today 2016, 21, 204-207. [CrossRef]

8. Newman, D.J.; Cragg, G.M. Natural Products as Sources of New Drugs over the 30 Years from 1981 to 2010. J. Nat. Prod. 2012, 75, 311-335. [CrossRef] [PubMed]

9. Cozza, G. The Development of CK2 Inhibitors: From Traditional Pharmacology to in Silico Rational Drug Design. Pharmaceuticals 2017, 10, 26. [CrossRef]

10. Cozza, G.; Pinna, L.A.; Moro, S. Kinase CK2 Inhibition: An Update. Curr. Med. Chem. 2013, 20, 671-693. [CrossRef] [PubMed]

11. Haidar, S.; Bouaziz, Z.; Marminon, C.; Laitinen, T.; Poso, A.; Le Borgne, M.; Jose, J. Development of Pharmacophore Model for Indeno[1,2-b]indoles as Human Protein Kinase CK2 Inhibitors and Database Mining. Pharmaceuticals 2017, 10, 8. [CrossRef] [PubMed]

12. Haidar, S.; Aichele, D.; Birus, R.; Hielscher, J.; Laitinen, T.; Poso, A.; Jose, J. In Vitro and in Silico Evaluation of Bikaverin as a Potent Inhibitor of Human Protein Kinase CK2. Molecules 2019, 24, 1380. [CrossRef]

13. Jagels, A.; Lindemann, V.; Ulrich, S.; Gottschalk, C.; Cramer, B.; Hubner, F.; Gareis, M.; Humpf, H.U. Exploring Secondary Metabolite Profiles of Stachybotrys spp. by LC-MS/MS. Toxins 2019, 11, 133. [CrossRef] [PubMed]

14. Jagels, A.; Hovelmann, Y.; Zielinski, A.; Esselen, M.; Kohler, J.; Hubner, F.; Humpf, H.U. Stachybotrychromenes A-C: Novel cytotoxic meroterpenoids from Stachybotrys sp. Mycotoxin Res. 2018, 34, 179-185. [CrossRef] [PubMed]

15. Olgen, S.; Gotz, C.; Jose, J. Synthesis and biological evaluation of 3-(substituted-benzylidene)-1,3-dihydro-indolin derivatives as human protein kinase CK2 and p60(c-Src) tyrosine kinase inhibitors. Biol. Pharm. Bull. 2007, 30, 715-718. [CrossRef] [PubMed] 
16. Gratz, A.; Gotz, C.; Jose, J. A CE-based assay for human protein kinase CK2 activity measurement and inhibitor screening. Electrophoresis 2010, 31, 634-640. [CrossRef]

17. Available online: https://www.rcsb.org/pdb/explore/explore.do?structureId=3C13 (accessed on 23 April 2018).

18. Schnitzler, A.; Gratz, A.; Bollacke, A.; Weyrich, M.; Kuckländer, U.; Wünsch, B.; Götz, C.; Niefind, K.; Jose, J. A $\pi$-Halogen Bond of Dibenzofuranones with the Gatekeeper Phe113 in Human Protein Kinase CK2 Leads to Potent Tight Binding Inhibitors. Pharmaceuticals 2018, 11, 23. [CrossRef]

19. Zuman, P. Reactions of orthophthalaldehyde with nucleophiles. Chem. Rev. 2004, 104, 3217-3238. [CrossRef]

20. D'Hollander, A.C.A.; Westwood, N.J. Assessment of the regioselectivity in the condensation reaction of unsymmetrical ophthaldialdehydes with alanine. Tetrahedron 2018, 74, 224-239. [CrossRef]

21. Martínez, R.; Geronimo, B.D.; Pastor, M.; Zapico, J.M.; Coderch, C.; Panchuk, R.; Skorokhyd, N.; Maslyk, M.; Ramos, A.; de Pascual-Teresa, B. Multitarget Anticancer Agents Based on Histone Deacetylase and Protein Kinase CK2 inhibitors. Molecules 2020, 25, 1497. [CrossRef]

22. Sasaoka, M.; Wada, Y.; Hasumi, K. Stachybotrydial selectively enhances fibrin binding and activation of Glu-plasminogen. J. Antibiot. 2007, 60, 674-681. [CrossRef] [PubMed]

23. Sawadjoon, S.; Kittakoop, P.; Isaka, M.; Kirtikara, K.; Madla, S.; Thebtaranonth, Y. Antiviral and antiplasmodial spirodihydrobenzofuran terpenes from the fungus Stachybotrys nephrospora. Planta Med. 2004, 70, 1085-1087. [CrossRef] [PubMed]

24. Hasumi, K.; Hasegawa, K.; Kitano, Y. Isolation and absolute configuration of SMTP-0, a simplest congener of the SMTP family nonlysine-analog plasminogen modulators. J. Antibiot. 2007, 60, 463-468. [CrossRef] [PubMed]

25. Xue, L.Y.; Chiu, S.M.; Oleinick, N.L. Staurosporine-induced death of MCF-7 human breast cancer cells: A distinction between caspase-3-dependent steps of apoptosis and the critical lethal lesions. Exp. Cell Res. 2003, 283, 135-145. [CrossRef]

26. Mosmann, T. Rapid colorimetric assay for cellular growth and survival: Application to proliferation and cytotoxicity assays. $J$. Immunol. Methods 1983, 65, 55-63. [CrossRef]

27. Molecular Operating Environment (MOE); Chemical Computing Group Inc.: Montreal, QC, Canada, 2013. 